\title{
ĐÁNH GIÁ CHẤT LƯợNG MÔI TRƯờNG NƯỚC MẠTT SÔNG HỒNG KHU VỤ̉C THÀNH PHỐ HÀ NỘI BĂNG ẢNH VỆ TINH SENTINEL - 2A
}

\author{
ĐINH TH! THU HIÊN \\ Viện Khoa học Công nghệ Cơ khí, Tụ̣ động hoá và Môi trường
}

\section{Tóm tắt:}

Đánh giá phân bố các thông số chất lượng nước sử dụng dữ liệu ảnh vệ tinh là một trong những ứng dụng cơ bản của công nghệ viễn thám cho môi trường nước. Các chỉ số như: độ đục, hàm lượng chất lơ lửng chuẩn hóa, chất diệp lục trong nước giúp chúng ta hiểu rõ hiện trạng chất lượng môi trường nước mặt. Bài báo này trình bày kết quả đánh giá chất lượng nước mặt sông Hồng đoạn chảy qua thành phố Hà Nội từ dữ liệu ảnh vệ tinh quang học Sentinel-2A. Kết quả nhận được có thể sử dụng phục vụ công tác quản lý, giám sát và đánh giá chất lượng nước mặt.

\section{Mỏ đầu}

Nước là tài nguyên thiên nhiên quý giá, là yếu tố không thể thiếu trong toàn bộ sự sống và các quá trình xảy ra trên Trái Đất [1]. Trong những năm qua, cùng với sự gia tăng dân số và phát triển kinh tế - xã hội, những ảnh hưởng tiêu cực của các hoạt động này đến nguồn nước khiến tình trạng ô nhiễm nước mặt diễn ra nghiêm trọng. Nghiên cứu đánh giá và giám sát chất lượng môi trường nước mặt trở thành một vấn đề cấp thiết đối với mọi quốc gia, góp phần bảo vệ và sử dụng bền vững nguồn tài nguyên nước mặt.

Trong hơn 3 thập kỷ qua, công nghệ viễn thám đã có những thành tựu hết sức to lớn trong lĩnh vực nghiên cứu Trái đất và trở thành một công cụ quan trọng phục vụ nghiên cứu, giám sát môi trường nói chung, môi trường nước mặt nói riêng. Nhiều nghiên cứu trên thế giới như của Weipi He (2008) [9], Olet (2000) [6], Doxaran (2007) [5], Moran et al. (1992) [7], Guzman et al. (2009) [8], Borup (2013) [10], Merry (2003) [11]... đã sử dụng tư liệu ảnh vệ tinh quang học SPOT, Landsat, MODIS nhằm xác định hàm lượng các thông số chất lượng nước như chất lơ lửng (suspended sediment), chất diệp lục (chlorophyll), chất hữu cơ hòa tan... Ở Việt Nam cũng đã có một số nghiên cứu sử dụng tư liệu ảnh vệ tinh quang học để đánh giá chất lượng nước khu vực ven biển Quảng Ninh - Hải Phòng [2], hồ Trị An (Đồng Nai) [4], hồ Tây (Hà Nội) [3]...

Vệ tinh Sentinel-2A được phóng lên quỹ đạo tháng 6 năm 2015, cung cấp ảnh ở 13 kênh phổ, trong đó các kênh 2 (490 nm), 3 (560 nm), 4 (665 nm) và 8 (842 nm) có độ phân giải không gian 10 m; các kênh 5 (705 $\mathrm{nm}), 6(740 \mathrm{~nm}), 7$ (783 nm), 8a (865 nm), $11(1610 \mathrm{~nm})$ và $12(2190 \mathrm{~nm})$ có độ phân giải không gian 20 m và các kênh 1 (443 nm), $9(940 \mathrm{~nm})$ và $10(1375 \mathrm{~nm})$ có độ phân giải không gian $60 \mathrm{~m}$. Với thời gian cập nhật 10 ngày và được cung cấp hoàn toàn miễn phí, ảnh vệ tinh Sentinel-2A là một nguồn tư liệu phong phú và quý giá phục vụ nghiên cứu tài nguyên thiên nhiên, giám sát môi trường. Mặc dù vậy, các nghiên cứu ứng dụng tư liệu ảnh vệ tinh Sentinel-2A trong giám sát môi trường nước Việt Nam còn ít được đề cập. Bài báo này 
trình bày kết quả xác định một số thông số đánh giá chất lượng nước như: chất diệp lục (chlorophyll-a), chất lơ lửng hòa tan (suspended material) và độ đục/trong của nước khu vực sông Hồng đoạn chảy qua thành phố Hà Nội sử dụng ảnh vệ tinh quang học Sentinel-2A.

\section{Phương pháp nghiên cứu}

\subsection{Cơ sở khoa học}

Theo Mobley (1999), giá trị phản xạ viễn thám $\mathrm{R}_{\mathrm{rs}}$ đối với nước được xác định bằng công thức sau [12]:

$$
R_{r s}=\frac{L_{w}}{E_{d}}
$$

Trong đó: $L_{w}$ là bức xạ rời khỏi mặt nước,

$E_{d}$ là bức xạ từ mặt trời hay bức xạ nguồn sáng đi tới mặt nước.

$$
E_{d}=\pi \cdot \frac{1}{R_{p}(\lambda)} \cdot L_{d}(\lambda)
$$

Với: $L_{d}$ là bức xạ phổ đo được, $R_{p}$ là tham số phản xạ, $\lambda$ là kênh ảnh tương ứng với bước sóng tương thích.

$L_{w}$ có dạng: $L_{w}(\lambda)=L_{u}(\lambda)-k \cdot L_{s}(\lambda)$

Với: $\mathrm{k}$ là tham số tỉ lệ giữa bức xạ bầu trời $L_{s}$ và bức xạ phản xạ trực tiếp từ bề mặt nước $L_{r}$.

Do đặc điểm thu nhận, ảnh viễn thám quang học nói chung để đưa vào sử dụng cần phải tiến hành hiệu chỉnh ảnh hưởng của môi trường khí quyển. Để hiệu chỉnh các ảnh hưởng của khí quyển đến chất lượng ảnh, ảnh gốc cần biến đổi từ giá trị số nguyên (digital number - $D N$ ) về ảnh phản xạ ở đỉnh khí quyển $\mathrm{R}^{*}$ (top of atmospheric - TOA), sau đó đưa về phản xạ bề mặt thông qua phép hiệu chỉnh khí quyển [12].

$$
R^{*}=T_{g}\left(R_{a}+R_{r}+T_{d} \cdot R_{w}\right)
$$

Trong đó: $R_{a}$ và $R_{r}$ là phản xạ sol khí (aerosol) và phản xạ Rayleigh, $T_{g}$ và $T_{d}$ là tham số truyền dẫn và khuyếch tán bức xạ trong khí quyển.

Như vậy, phản xạ viễn thám $R_{r s}$ được tính theo mối quan hệ sau [12]:

$$
R_{r s}=\frac{R_{w}}{\pi\left(1+S \cdot R_{w}\right)}
$$

Ở đây $S$ là giá trị suất phân chiếu bầu trời (albedo).

Từ những phân tích trên có thể kết luận rằng, phản xa viễn thám xác định từ tư liệu ảnh vệ tinh quang học tuân theo quy luật khách quan khi có tương tác của ánh sáng vào đối tượng nước [2, 12].

\subsection{Phương pháp xác định các chỉ số chất lượng nước}

Các thông số cơ bản đánh giá chất lượng nước từ tư liệu viễn thám cơ bản là các chất tạo màu trong nước như hàm lượng chất lơ lửng, hàm lượng chất diệp lục (chlorophyll-a), độ đục/trong của nước và hàm lượng các chất hữu cơ hòa tan. Trong nghiên cứu này, để đánh giá chất lượng nước mặt, tác giả sử dụng các chỉ số bao gồm chỉ số chất diệp lục (Chl-I - chlorophylla index), chỉ số độ đục/trong của nước (TI turbidity index) và chỉ số vật chất lơ lửng chuẩn hóa (NSMI - Normalized suspended material index) $[13,14,15]$.

Chỉ số độ đục của nước và chỉ số chất diệp lục được tính theo [14]:

$$
\begin{gathered}
T I=\frac{\rho_{R E D}+\rho_{\text {GREEV }}}{\rho_{\text {BLUE }}} \\
C h l-I=\frac{\rho_{\text {GREEV }}+\rho_{\text {NIR }}}{\rho_{\text {RED }}}
\end{gathered}
$$

Chỉ số chất lơ lửng chuẩn hóa NSMI được tính theo [13]:

$$
N S M I=\frac{\rho_{R E D}+\rho_{\text {GREEN }}-\rho_{\text {BLUE }}}{\rho_{\text {RED }}+\rho_{\text {GREEN }}+\rho_{\text {BLUE }}}
$$

Đối với ảnh Sentinel-2A, để tính các chỉ số này sử dụng phản xạ phổ tại các kênh 2 (blue), kênh 3 (green), kênh 4 (red) và kênh 8 (NIR). 


\section{Kết quả và thảo luận}

Khu vực nghiên cứu được lựa chọn là sông Hồng khu vực thành phố Hà Nội. Tư liệu sử dụng là ảnh vệ tinh Sentinel-2A chụp ngày 20 tháng 10 năm 2016 (xem hình 1). Để xác định các chỉ số chất lượng nước, trong nghiên cứu sử dụng các kênh ảnh: kênh xanh lam (kênh 2), xanh lục (kênh 3), đỏ (kênh 4) và cận hồng ngoại (kênh 8) với độ phân giải không gian $10 \mathrm{~m}$, giúp đánh giá chất lượng nước mặt một cách chi tiết hơn so với ảnh vệ tinh Landsat hay Aster.

Ảnh Sentinel-2A sau khi thu thập được tiền xử lý nhằm loại bỏ các sai số về phổ và sai số hình học. Ở bước tiếp theo, giá trị số nguyên của ảnh được chuyển đổi sang giá trị bức xạ điện từ, sau đó xác định phản xạ đỉnh khí quyển (TOA). Để xác định phản xạ phổ bề mặt phục vụ tính các chỉ số chất lượng nước, trong nghiên cứu sử dụng phương pháp "trừ đối tượng tối" - DOS (Dark Object Subtraction) [16].

Kết quả xác định các chỉ số độ đục, chỉ số chất diệp lục và chỉ số chất lơ lửng NSMI từ ảnh vệ tinh Sentinel-2A ngày 20/10/2016 được trình bày trên các hình (xem hình 2).

Từ các ảnh chỉ số này, khu vực sông Hồng được tách riêng, giá trị các chỉ số chất lượng nước sẽ được phân thành 8 khoảng theo phương pháp "natural breaks". Kết quả được trình bày trên các hình (xem hình 3).

Kết quả đánh giá phân bố thông số độ

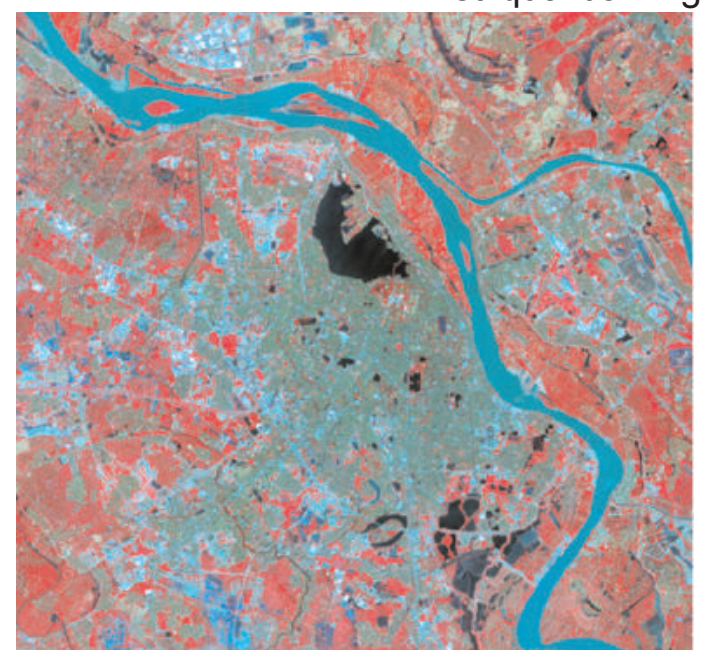

Hình 1: Tư liệu ảnh vệ tinh Sentinel-2A khu vực Hà Nội ngày 20/10/2016
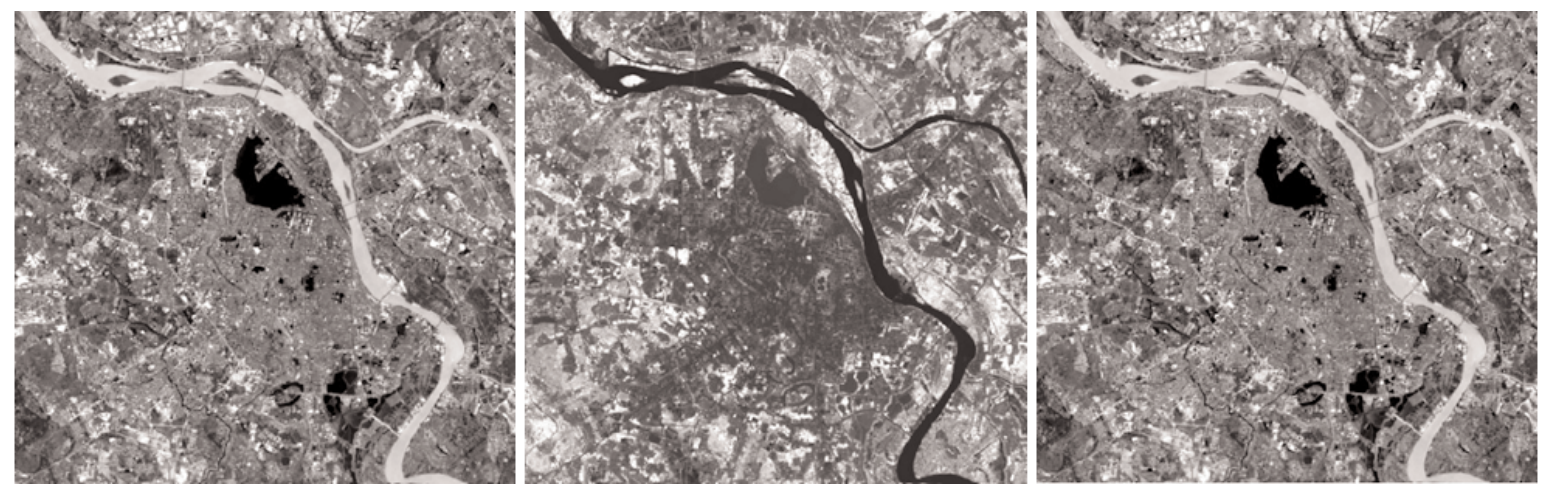

Hình 2: Các chỉ số độ đục (a), chất diệp lục (b) và chất lơ lửng (c) xác định từ ảnh Sentinel-2A 
đục cho thấy: nước sông Hồng có độ đục tương đối cao; độ đục cao nhất tập trung ở khu vực gần bờ và ven các bãi bồi giữa sông Hồng; giá trị độ đục cao cũng được ghi nhận ở khu vực tiếp giáp giữa sông Hồng và sông Đuống, sông Bắc Hưng Hải. Nguyên nhân dẫn đến nước có độ đục cao ở những khu vực trên là do nguồn nước thải sinh hoạt, nước thải của các nhà máy, xí nghiệp chủ yếu được xả thẳng ra sông Hồng. Bên cạnh đó, hoạt động sản xuất của người dân tại các khu vực bãi bồi cũng như khu vực tiếp giáp giữa sông Hồng và các chi lưu cũng là những nguyên nhân làm cho nước sông Hồng có độ đục cao. (xem hình 3a)

Hàm lượng diệp lục trong nước sông Hồng đoạn chảy qua thành phố Hà Nội nhìn chung không cao. Các khu vực có hàm lượng chất diệp lục cao tập trung chủ yếu ở ven bờ và ven các bãi bồi. Càng ra xa bờ, hàm lượng chất diệp lục càng giảm. Nguyên nhân có thể là do chất dinh dưỡng ở khu vực ven bờ cao, tạo điều kiện cho các loại thực vật ngập nước, thực vật phù du phát triển mạnh. (xem hình 3b)

Chỉ số chất lơ lửng biến đổi mạnh từ khu vực ven bờ ra và các khu vực ven các bãi bồi giữa sông Hồng cũng như nợ tiếp giáp giữa sông Hồng với các chi lưu. Chỉ số chất lơ lửng có quan hệ mật thiết với chỉ số độ đục của nước, tại các khu vực có chỉ số chất lơ lửng cao thì độ đục trong nước cũng cao. (xem hinh 3c)

\section{Kết luận}

Ảnh vệ tinh quang học Sentinel-2A với ưu điểm thời gian cập nhật ngắn và được cung cấp hoàn toàn miễn phí là nguồn tư liệu quý giá trong nghiên cứu, đánh giá chất lượng nước mặt.

Phân tích kết quả nhận được cho thấy, nước mặt khu vực sông Hồng đoạn chảy qua thành phố Hà Nội có hàm lượng độ đục và chất lơ lửng cao, đặc biệt ở khu vực ven bờ và ven các bãi bồi do tác động của nguồn nước thải sinh hoạt và nước thải công nghiệp của các nhà máy, xí nghiệp ven sông. Trong khi đó, hàm lượng chất lơ lửng trong nước mặt sông Hồng tương đối thấp và chủ yếu tập trung ở ven bờ, nơi các loại thực vật ngập nước và thực vật phù du phát triển mạnh.

Kết quả nhận được trong nghiên cứu là một nguồn thông tin hữu ích, giúp các nhà quản lý đưa ra những biện pháp theo dõi, ứng phó và giảm thiểu thiệt hại do ô nhiễm nước mặt gây ra. $O$

\section{Tài liệu tham khảo}

[1]. Nguyễn Thanh Sơn (2005), "Đánh giá tài nguyên nước Việt Nam", Nhà xuất bản Đại học Quốc gia Hà Nội, 2005.

[2]. Lương Chính Kế (2014), "Sử dụng công nghệ viễn thám và GIS xây dựng cơ sở dữ liệu thành lập bản đồ diễn biến vùng ô nhiễm nguồn nước thải từ các khu công

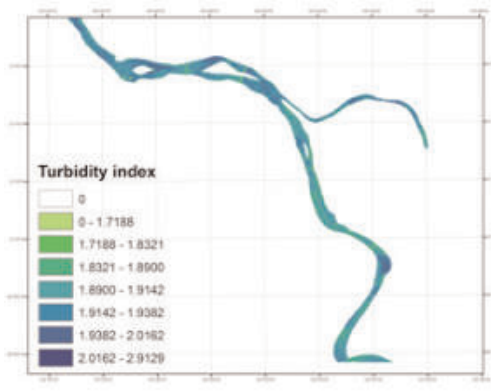

a)

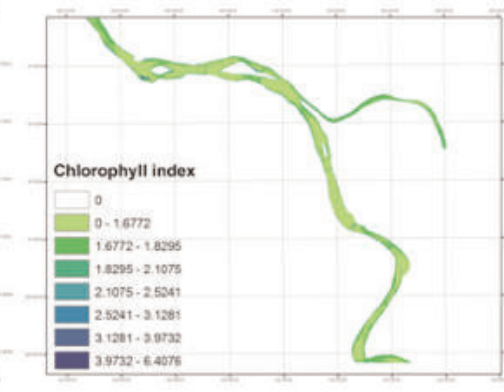

b)

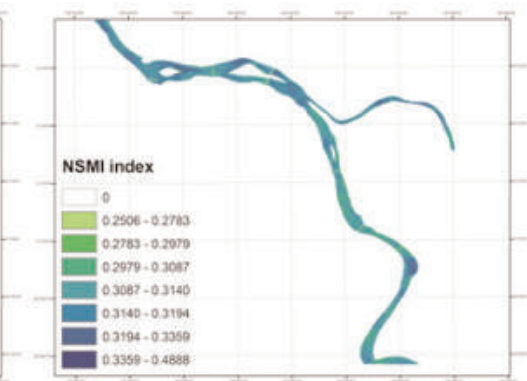

c)

Hình 3: Kết quả xác định phân bố thông số độ đục (a), chất diệp lục (b) và chất rắn lơ lửng (c) khu vực sông Hồng đoạn chảy qua Hà Nội 
nghiệp, đô thị nhằm đưa ra cảnh báo các vùng có nguy cơ ô nhiễm thuộc vùng kinh tế trọng điểm miền Bắc", Dự án nghiên cứu khoa học, Cục Viễn thám quốc gia, Bộ Tài nguyên và Môi trường.

[3]. Nguyễn Thị Thu Hà, Bùi Đình Cảnh, Nguyễn Thiên Phương Thảo, Bùi Thị Nhị (2016), "Thử nghiệm mô hình hóa sự phân bố không gian của hàm lượng chlorophyll-a và chỉ số trạng thái phú dưỡng nước Hồ Tây sử dụng ảnh Sentinel-2A", Tap chí Khoa học Đại học Quốc gia Hà Nội, chuyên san Các Khoa học Trái đất và Môi trường, tập 32, số 2S, trang $121-130$.

[4]. Trinh Le Hung (2015), "Mapping suspended sediment concentrations in surface water of Tri An lake using remote sensing and GIS", Journal of Science, Natural Sciences Issue, Hue University, Vol.96(8), $59-70$.

[5]. David Doxaran, Jean - Marie Froidefond, Samantha Lavender, Patrice Castaing (2007), "Spectral signature of highly turbid waters application with SPOT data to quantify suspended particulate matter concentrations", Remote sensing of Enviroment, Vol. 81, pp. 149 - 161.

[6]. Emmanuel Olet (2010), "Water quality monitoring of Roxo reservior using LANDSAT images and In - situ measurements",
International institude for geo - information science and earth observation enschede, the Netherlands, $69 \mathrm{pp}$.

[7]. Moran, M.S. et al (1992), "Evaluation of simplified procedures for retrieval of land surface reflectance factors from satellite sensor output", Remote Sensing of Environment 41:169-184.

[8]. Vilmaliz Rodriguez - Guzman, Fernando Gilbes - Santaella (2009), "Using MODIS $250 \mathrm{~m}$ Imagery to Estimate Total suspended sediment in a Tropical open bay", International journal of systems applications, engineering \& development, Issue 1, Vol. 3, pp. $36-44$.

[9]. Weiqi He (2008), "Water quality monitoring in slightly - polluted body through remote sensing - a case study in Guanting Reservoir Beijing", China, Front. Environ. Sci. Engin, Vol. 1, 11 pp.

[10]. Borup M.D., Victor N.A. Narted (2013), "Mapping and modeling chlorophylla concentration in Utan lake using Landsat 7 ETM+ imagery", WEFTEC 2013.

[11]. Merry C. (2003), "Water quality monitoring with remote sensing", Ohio geospatial technologies conference for Agriculture and Natural resources, 2003, Columbus, Ohio. $\mathrm{O}$

\section{Summary}

\section{Assessment of surface water quality in the Red river of Hanoi city using Sentinel- 2A high spatial resolution optical imagery}

Dinh Thi Thu Hien, Institute of Mechanical Science and Technology, Automation and Environment

Assessment of water quality parameters is a key topic of remote sensing applications for water environment. Water quality parameters, such as turbidity index, normalized suspended material index (NSMI) and chlorophyll-a index in surface water helps better understand the water quality. This study presents results of surface water quality assessment in Red river of Hanoi city using Sentinel-2A high spatial resolution optical imagery. The results obtained in the study can be used to serve the management, monitoring and evaluation of surface water quality. $O$ 